\title{
A Study on the Directing Direction of Exhibition in the Corporate Exhibition Spaces
}

\author{
Seung-Wan Ju \\ Dong-Eui University \\ gauace@naver.com
}

\begin{abstract}
The exhibition space of the Korean company focused on expressing the future of the company, causing confusion among users due to the indiscriminate promotion of wartime delivery, and is not a contribution of the company due to the direction of partial display.

Thus, the study analyzed the cases of the corporate exhibition space and presented the direction of the exhibition space of three companies.

First, through exhibition that combines education and cultural functions, the exhibition space will be provided to children through educational space and cultural function space, and secondly, the exhibition space will be provided to customers of the public through exhibition space.

In the future, companies will create a future-oriented corporate exhibition space that can contribute to the improvement of the company's knowledge through the corporate exhibition space, securing potential customers, and contributing to the development of cultural services and regional culture.
\end{abstract}

Keywords: Exhibition, Corporate Exhibition Space, Exhibition Directing, Corporate Image ${ }^{l}$

\section{Introduction}

Long since the global free market came to start, businesses have been in the state of severe competition for their survival. Furthermore, they are having trouble with establishing various goals and strategies to meet increasingly complicated corporate environment.

Modern conglomerates' exhibition spaces have been conducive to the development of many areas, such as culture, education and tourism beyond its original functions as a method of promotion and marketing. Furthermore, they are playing a key role as a multi-purposed cultural complex which contributes to betterment of brand imaging, local culture and even national dignity by delivering various issues regarding visions and ethics on the part of businesses.

However, exhibition spaces in Korea are so focused on spreading corporate images and physically concentrated on their spaces that they causes customers' confusion by excessive stimulus from senseless exhibition, which does not contribute to delivering appropriate corporate images.

Thus, this study suggests the direction of better exhibition by analyzing some cases of corporate exhibition spaces and seeks for the development of multi-purposed cultural complex that can contribute not only to communicating with customers and offering a better cultural

\footnotetext{
${ }^{1}$ Article history:

Received (March 18, 2019), Review Result (April 19, 2019), Accepted (May 20, 2019)
} 
service but also to obtaining potential customers and serving further profits on the part of business.

\section{Theoretical background}

\subsection{Display}

Display refers to the objects arranged based on discreet interpretation and on specific ideas, rather than to simple arrangement of individual objects. [1]That is, display is intended to deliver information. So the way with which senders of information and receivers of it communicate is considered important. Therefore, rather than simple arrangement of objects, display would be an active and affirmative form to deliver specific information- for whom it is designed, what it expresses, and how it is represented. [2]

\subsection{Direction of display}

The need for explaining exhibits effectively leads to that for exhibition presentation media. It is very important for us to understand appropriate situations about exhibits, choose right ways of display, and use proper exhibition media. [3]

Table 1. Exhibition Presentation Madia Classification

\begin{tabular}{|c|c|c|}
\hline Directed Media & Division & Transmission Medium \\
\hline \multirow{3}{*}{ Planar Medium } & Explanation & Graphic Panel, Operation Panel etc \\
\hline & Photo & General Photo, Wide Screen, Space Photo, Croma Color etc \\
\hline & Redord Picture & Represent historical facts or situations in pictures or photographs \\
\hline \multirow{5}{*}{$\begin{array}{l}\text { Stereoscopic } \\
\text { Medium }\end{array}$} & Real & Specimen, Real Thing \\
\hline & Clone & Original Restoration , Hypertrophy Restoration \\
\hline & Model & Physical Model, Operational Model, Diorama etc. \\
\hline & Showcase & Exhibition by showcase \\
\hline & Stand & Basic form of exhibition by exposing the exhibits \\
\hline Video Media & Video & Beam Project, Grand Mirage, Multi-vision, Magic-vision etc \\
\hline $\begin{array}{l}\text { Acoustic } \\
\text { Medium }\end{array}$ & Sound & Sound Effects, Synthesizer, Directional Speaker etc \\
\hline $\begin{array}{l}\text { Composite } \\
\text { Medium }\end{array}$ & Video + Sound & Touch Screen, Laser System, Vision Station etc \\
\hline
\end{tabular}

It is the basic purpose of the exhibition hall to easily understand the contents of the exhibition to the visitors, accurately communicate the intentions of the exhibitor and to form consensus with the visitors. Therefore, new exhibition design techniques are developed and developed in order to increase the understanding and interest of the visitors 
by adopting stereoscopic and visual exhibition presentation techniques in the past, by breaking away from the planar and listed exhibition presentation techniques of the past.

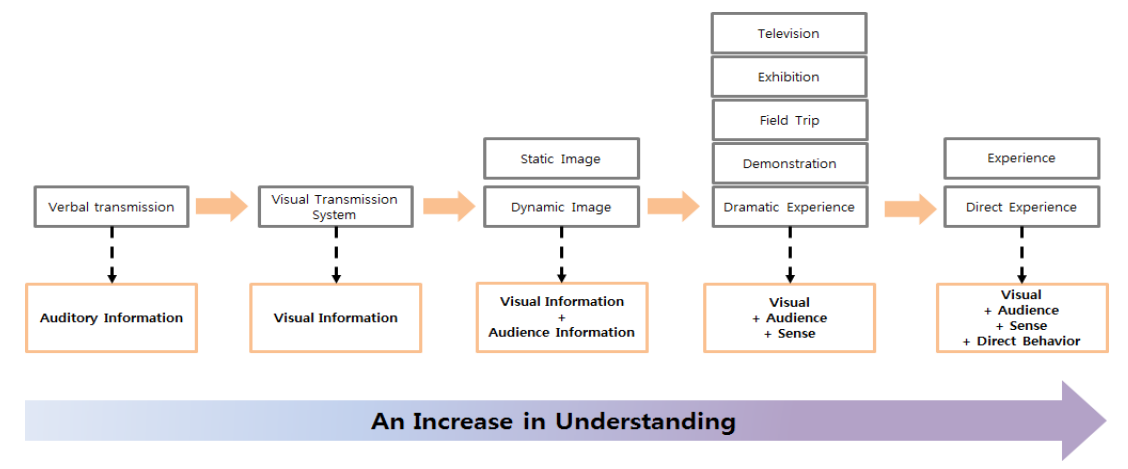

Figure 1. An Interpretation of Exhibition Presentation Madia[4]

\subsection{Corporate Display Space}

In terms of business, exhibition is a time-sensitive market place made by individuals or organizations where sellers and buyers pursue mutual interaction for the sake of purchasing the products and services, displayed on site or expected to be exhibited in the near future. The terms for display vary according to how they are used: Trade fair, Trade show, Exhibition and Exposition. [5]

Display has qualified and targeted customers as its users, which is an exclusive feature display has distinct from other promotion methods. For such users, organizations have their purposes such as imprinting their images into customers' mind and pursuing their profits, in which point display space has evident purposes and targets.

\subsection{Display space and Corporate image}

Corporate image is an image that customer has to a company, which shows a certain company's traits, originality, and management philosophy revealed outside. In order to obtain such an image, organizations pay more weight on effective marketing strategies, especially on space. Because corporate image is revealed in via of human activities, display space includes not only various special traits but also a number of human traits in its shape and content. [6]

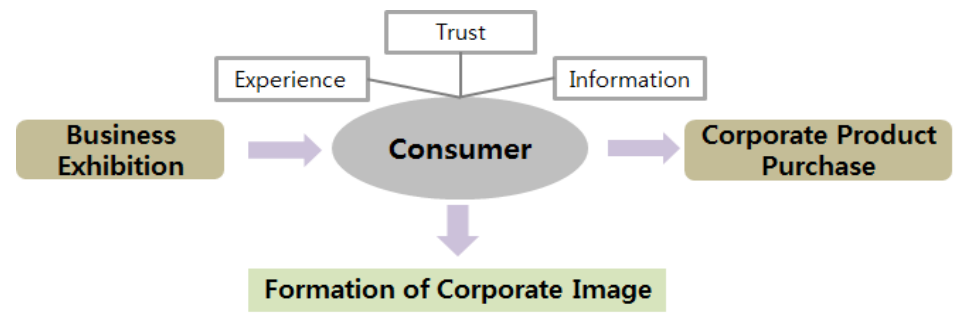

Figure 2. The Relationship between Corporate Exhibition and Corporate Image [7]

Therefore, display space offers its users with a space stimulating their senses by giving practical experience to users. The space gives help to differentiate an organization's products 
from those from other companies. [8] Furthermore, it becomes an evident process to construct an organization's vision for the future by giving its customers an experience of corporate image. [9]

However, corporate display spaces in Korea have failed to deliver its own original corporate image to customers. More worse, the spaces are merely used to display its' products. It will be clear-cut that future-oriented displace spaces are not fully achieved that reflect sudden change of society and various life styles of customers'.

\section{Cases of corporate display space}

\subsection{KT Olleh Square}

Olleh Square from KT representative of Korea's telecommunication industry is both a corporate display space and cultural space that enable the organization to communicate with its customers. It characterizes a way called 'Ole-gil' -the name of tracking course in Je-ju.

Olleh Squre, not limited to the purpose of IT technology display and promotion, presents 8 thematic sections composed of Dream Hall, Ech Lounge, Home Lounge, Mobile Lounge, Service Lounge, Cafe \& Tech Lounge, Facade \& Tech Lounge, Products Corner, which provide new conceptual space harmonized with the rest in intra-city nature, culture, and technology. Starting with its motto "NEW," the space exposes brand identity to all of the things including video clips, its products, information leaflets, and disposable stuffs.

\subsection{KOEN Yeong-Heung Energy Park}

KOEN Yeong-Heung Energy Park offers a famous field-trip service so that visitors can have a great deal understanding about electricity and energy and experience information of domestic power industry in a direct way.

The first floor of the exhibition hall is largely a play culture space intended for education where it offers various and interesting experiences. The second floor is a space to inform visitors of the history and system of power industry. Harmony Hall is a complex culture space leading local culture and art by providing quality contents such as the latest movies and musicals to the locals who live in regions far from quality culture.

\subsection{K-Shoes Center}

K-Shoes Center was built for the purpose of assisting Korea's shoe industry in its global marketing and promoting products from Busan, which is called a mecca of Korean shoe industry. It is a seven-story building consisting of shoe multi-public relations center, history center, business center and manpower training center.

Multi-public relations center on the first floor assumes displaying latest products, introducing new technology about shoe manufacturing, and informing of infrastructures such as small business support centers for shoe, artificial leather and bag. The history center on the second floor displays traditional korean shoes and earlier products made in Korea. Business center operates on the third floor and manpower training center on the fourth and fifth floor is used for educating professional manpower for the industry. The sixth and seventh floor are used for rental space for start-ups in this field.

\section{Case study and proposal on the direction of display design}


The corporate display spaces from the cases above are maintained consistently in its design concept for managing corporate images and administered systematically and integratively for brand image that organizations regard as an important asset. Furthermore, The companies in the cases create and operate a number of contents to raise corporate image and make efforts to establish the identity of display space design. And the display spaces in the cases reflect the history and philosophy of the organizations and seem to have the characteristic of complex cultural space which makes the cooperation of local economy possible.

This study, therefore, makes three summarized suggestions on effective ways for display direction over simple corporate display.

First, if a display space makes affinity with customers through educational and cultural functions, it will be accepted without resistance from customers because it can offer a chance to give educational experience to children and to come closer to adults with newness.

Second, a display direction harmonizing experience and emotion should be presented. The display direction with experience and emotion is one that stimulates visitors'senses whereby it allows visitors to recognize the contents that organization want to offer faster and more accurately in that visitors can participate in the experiences directly. [9] Through the experience from the direct participation, visitors come to be stimulated, which also makes an educational effect. This type of display space is able to play a role as a cultural space, to offer various spaces of experience, and to imprint a favorable corporate image to customers. This is where profits are increasingly generated and organizations would have benefit from the space. [10]

Third, through the digitalized direction based on computer technology, organizations can integratively control the system of space around the clock. Digitalized display space makes customized service for customers possible, which enables organizations to communicate with customers within a more horizontal relation.

\section{Conclusion}

Corporate display space is intended not to make corporate's social contribution by providing a socio-cultural complex but to offer customers with a positive image through direct experience of products and strategic utilization of space. Therefore, corporate display space should encourage communication between organizations and customers by means of proper direction of display spaces that corresponds with customers' needs.

The direction of corporate display is the optimal way to imprint positive images into customer's mind by delivering the information and intent of the space in correspondence to customers' needs and desires.

This study analyzes several cases in Korea to raise awareness of corporate image and suggests the following three-fold dimensions for appropriate direction of display space.

First, display space should make a uninterrupted acceptance from customers by offering educational function to children and cultural space to adults which cause affinity with organizations through delicate direction.

Secondly, it should give customers indirect corporate images by providing them with a space of experience through the direction presenting practical experience and emotional stimulus.

Last, it should present the horizontal communication between organizations and customers that enables the space to give customized services based on computer technology and digitally crafted display design.

The suggestions above would be hard to be made in a short time but, in that the derivative effects of space direction will affect a variety of corporate activities, organization should pay more attention to the direction of display space. 
It is expected that corporate display space will increase, followed by the utilization of various and novel media. But despite the fact that the forms of display space and the ways of directing display will be developed and specialized, there is still a need for facility that can accommodate many positive functions from corporate display and play an important role to give organizations the chance of social contribution.

If a lot of comparative studies about the direction of corporate display both abroad and in Korea, suggested ideas in this study may well be meaningful.

\section{References}

[1] Ju-Yeon. Kim, A Study on the Process of Contemporary Museum Exhibition Planning \& Evaluation, Guk-Min University Doctor's Thesis (2002), pp.9-12.

[2] Ju-Hyeong. Lee, A Study on the Structure of Exhibition Scenario and the Programming of Space production, Hong-Ik University Master's Thesis (2000), pp.3-4.

[3] Suk-Gyeong. Song, Design Experiential Exhibition Space Plan for the Development of Children's creativity, Hong-Ik University Master's Thesis (2011), p.26.

[4] Seok-Hwan. Yu, A Study on Co-Expo Proposal through Convergence Environment Construction, Hong-Ik University Doctor's Thesis (2003), pp.59-60.

[5] Gyu-Ra. Park, Characteristics of Exhibitors and Study of Visitors, Hong-Ik University Master's Thesis (2004), p.5.

[6] Hyeong-Suk. Kim, A Study on User Behavior in Exhibition Space, Dong-Seo University Master' Thesis, (2007), pp.9-10.

[7] Seong-Hyeon. Ryu, A Stydy of Display Space Program for Imprint Company Image, Seong-Gyun-Gwan University Master's Thesis (2008), p.8.

[8] Gyu-Ra. Park, Characteristics of Exhibitors and Study of Visitors, Hong-Ik University Master's Thesis (2004), p.5.

[9] Won-Gil. Kim, A Study of the Criteria to Plan Temporary Exhibition of Museum, Hong-Ik University Doctor's Thesis (2019), p.102.

[10] Sung-Wok. Sin, A Study on Characteristics of Exhibitions according to the Diversification of Exhibition Direction In the Insect Ecology Museum, Gun-Kuk University Master's Thesis (2019), p.23. 